\title{
Shlomit Levy: a Pioneer in the Structural Theory of Well-Being
}

\author{
Shlomit Levy ${ }^{1}$
}

Published online: 21 November 2016

(C) Springer Science+Business Media Dordrecht and The International Society for Quality-of-Life Studies (ISQOLS) 2016

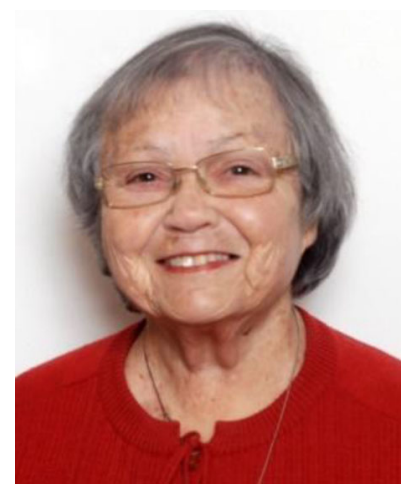

I was born in Jerusalem and received my B.A. (Sociology and International Relations), M.A Cum Laude (Contemporary Jewry), and Ph.D. in Jewish Identity from the Hebrew University of Jerusalem. My academic career began in 1963 as research coordinator with Professor Simon Herman at the Psychology Department of the Hebrew University. From 1965 until 1996, I was affiliated with the Guttman Institute of Applied Social Research. Concomitantly, from 1978 to 1989 I served as a research consultant to the Social Science Faculty of the Hebrew University, and between 1992 and 2000, I taught at the School of Social Work where I also conducted a seminar on well-being. Since 2002, I have been a visiting researcher at the Institute of Contemporary Jewry of the Hebrew University.

In addition, I was actively involved in a number of international projects, such as the Working Group on Values and Social Problem Indicators for Contemporary Europe

Shlomit Levy

shlomit.levy2@mail.huji.ac.il

1 Institute of Contemporary Jewry, the Hebrew University of Jerusalem, Jerusalem, Israel 
(1976-1984) and tutored many workshops with Professor Guttman on facet theory and nonmetric data processing in various universities in Europe, the United States, and Israel. I have presented in international scientific conferences, in some as a keynote speaker, and published extensively, inter alia on well-being, facet theory, social indicators, values, Jewish identity, and intelligence.

Upon joining the Institute of Applied Social Research, I worked with Guttman on a number of projects, through which I became acquainted with his latest multivariate data analysis techniques and with Facet Theory. One afternoon, on leaving the office, he suddenly said, "I've given it a lot of thought; you shall be my partner." This was the beginning of a wonderful, creative, scientific partnership that lasted two decades, until his death in October, 1987.

For many years I was Guttman's closest collaborator in developing facet theory, a research strategy that integrates formal definitions of research contents with intrinsic data analysis. I was among the founders of the International Facet Theory Association (FTA), and served as its president in the years 2001-2003. I was also the scientific organizer of international conferences on facet theory in Jerusalem (1991) and Ljubljana (2003).

A major concern of my work is well-being regarding multivariate conceptualization and comparative study of the structural perception of well-being. While working on social problem indicators in the early 1970's, I began developing the topic of wellbeing. During my stay as a visiting researcher at the Institute of Social Research at the University of Michigan in Ann Arbor in 1972, Professor Campbell and his team were working on the project, 'Quality of American Life.' I was pleasantly surprised to discover the similarity between the questions they asked and what we asked in Israel. I suggested they run the Guttman-Lingoes SSA (Smallest Space Analysis) geometric technique on the questions relating to personal well-being which were similar to those used in Israel. The results showed the same circular configuration of the points according to their content. At the center of each circle (radex) - for the U.S. and for Israel-lies the assessment of the respondent's feeling of happiness. Happiness is closest to variables that relate to the respondent's internal and primary environment and less to the resources (e.g. income, dwelling, health, education). Variables concerning secondary environment, like neighborhood and town, tend to be even less correlated with happiness. This means that feelings of well-being in physical and instrumental aspects of life cannot predict personal happiness as well as sociopsychological (personal and interpersonal) aspects can. Here we see the power of the SSA technique in comparative analysis: it enables us to see the same structural lawfulness concerning human behavior. These results spurred me to intensify and expand my work on well-being.

The term "well-being" is multivariate, and its study requires a definitional framework to facilitate a view of this multivariate complexity. Formal definitions are required for establishing successful theories leading to scientific generalizations, i.e. lawfulness. Guttman's mapping sentence is intended to meet this requirement; it specifies the psychological response in terms of several facets that classify the content of the observations on well-being (Levy and Guttman 1975). Each facet is one way of classifying the research variables according to some rule and is specified as having a role in partitioning the empirical space. One facet is the social group under study. Some other facets are life domain, modality of the assessment, and social 
environment. The environment facet is treated as ordered from the "self" to "community" or "State". Hence, this definitional framework incorporates the study of both personal and national well-being.

Morrison et al. (2011) indicate the lack of well-being studies that examine the interrelations between personal and national satisfaction, which are important for the understanding of societal well-being. They found only two major studies that examined this issue: One of them is Levy and Gutman (1975), which was later extended and replicated (Levy 1990).

Data analysis revealed that the structure of the interrelations between the questions is multi-dimensional according to the roles that the facets play in partitioning the SSA space. Moreover, personal well-being items tend to correlate more within the stratum of self than within the stratum of community well-being (Levy and Guttman 1975).

Thus the use of the variety of facets of the mapping sentence promotes systematic development of a structural theory of well-being in a cumulative fashion. An example of this can be seen in the development of the structural theory of personal well-being through incorporating well-being of the self's personality (Levy and Sabbagh 2008).

\section{References}

Levy, S. (1990). The mapping sentence in cumulative theory construction: wellbeing as an example. In J. J. Hox \& J. de Jong-Gierveld (Eds.), Operationalization and research strategy (pp. 155-177). Amsterdam: Swets \& Zeitlinger.

Levy, S., \& Guttman, L. (1975). On the multivariate structure of wellbeing. Social Indicators Research, 2, 361-388. Also In A. C. Michalos (Ed.) (2005). Citation classics from social indicators research (pp. 145172). Dordrecht: Springer.

Levy, S., \& Sabbagh, C. (2008). The wellbeing of the self's personality: a structural analysis. Social Indicators Research, 89(3), 473-485.

Morrison, M., L. Tay, \& Diener, E. (2011). Subjective wellbeing and national satisfaction: findings from a worldwide survey. Psychological Science 22(2), 166-171. 